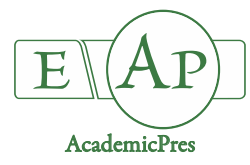

\title{
The Effect of Therapeutic Horticulture Activities on People in Depression and Kynurenine Pathways
}

\author{
Timea HITTER (BURU) ${ }^{1}$, Éva KÁLLAY ${ }^{2}$, Loredana E. OLAR ${ }^{3}$, \\ Răzvan ŞTEFAN ${ }^{3}$, Erzsebet BUTA ${ }^{1}$, Silvia CHIOREAN ${ }^{1}$, \\ Maria CANTOR ${ }^{1 *}$, Ionel PAPUC ${ }^{3}$ \\ ${ }^{1}$ University of Agriculture Sciences and Veterinary Medicine, Faculty of Horticulture, 3-5 Mănăştur street, 400372, Cluj-Napoca, \\ Romania; timea.hitter@usamvcluj.ro; ebuta2008@yahoo.com; silvia.chiorean@usamvcluj.ro; marcantor@yahoo.com (*corresponding author) \\ ${ }^{2}$ Babes Bolyai University, Faculty of Psychology and Educational Sciences, 1 Mihail Kogălniceanu street, 400084, Cluj-Napoca, \\ Romania; evakallay@gmail.com \\ ${ }^{3}$ University of Agriculture Sciences and Veterinary Medicine, Faculty of Veterinary Medicine, 3-5 Mănăştur street, 400372, Cluj-Napoca, \\ Romania; olarloredanaelena@yahoo.com;rstefan@usamvcluj.ro;papuc_i@yahoo.com
}

\begin{abstract}
The article presents the results of a study conducted to assess change in depression severity, and modification in the kynurenine pathway at participants. Presently, depression is one of the most regularly encountered mental illnesses. Research based on experimental studies indicated the beneficial effects of activities conducted in nature are reducing self-reported anger, fatigue, anxiety, stress and depression. The present study was conducted by measuring depression on both the subjective (Beck Depression Inventory) and the objective (spectrophotometric analysis) levels, to obtain more relevant information regarding the real change in depression levels, during the therapeutic horticulture intervention. Consequently, depression is assessed with the BDI doubled the data by assessing the levels of kynurenine and kynurenic acid obtained from biological samples. Results indicate that the levels of depression measured with the BDI have significantly decreased after the Therapeutic Horticulture Sesions. An even better result regards the fact that the significance of this change was not only statistical, but also clinical. Analysing the kynurerine and kynurenic acid concentrations, differences were observed amongst subject during the research study.
\end{abstract}

Keywords: biomarker; gardening activities; mental health; nature-based interventions

Abbreviations: BDI: Beck Depression Inventory; HT: horticulture therapy; KYN: kynurenine; KYNA: kynurenic acid; TH: therapeutic horticulture

\section{Introduction}

The last four-five decades have witnessed an unprecedented increase in the number and the diversity of life-challenges. This phenomenon has additionally been aggravated by the disruption of the traditional and stable life-guiding interpretive frameworks (Amundson, 2006; Nolen-Hoeksema, 2003), which have seriously challenged humans' abilities to adapt to the new life-conditions (Woolfolk et al., 2007). Not surprisingly, a constantly increase of population fraction has presented significant symptoms of stress, impairing different aspects of functioning (physiological, behavioral, cognitive, emotional, social etc.) (Falvo, 2005; Levenson, 2006; Aldwin, 2007; Banyard et al., 2009; Kendall-Tackett, 2009; National Comprehensive Cancer Network, 2009; Lanius et al., 2010; Pennebaker and Chung, 2011). The number of those who suffer of mental illness of clinical intensity has been constantly increase along the years, depression being one of the most frequently encountered mental illnesses (Andrade et al., 2003; Cunningham et al., 2006; Cuijpers et al., 2007; Weehuizen, 2008). The lifetime prevalence of depression ranges between $3-16.9 \%$ and $4.4 \%$ of the global population suffering of this extremely debilitating mental health conditions (Kessler et al., 2003; WHO, 2017). Worldwide, depression is estimated to affect $5.8 \%$ of all men and $9.5 \%$ of 
all women in any given year (Gonzalez et al., 2009), the female:male ratio of major depression remained similar along the years, 1.7:1 respectively (Albert, 2015). In order to illustrate this increase in mental illness, only in the USA, the prescription of antidepressants (the third most frequently prescribed drugs during 2005-2008) has recorded a 400\% increase between 1988-1994 to 2005-2008 (Pratt et al., 2011). Being a huge socio-economic burden, depression is predicted to become the second most serious disease by 2030 (Mathers and Loncar, 2006; Gustavsson et al., 2011; Wittchen et al., 2011).

Unfortunately, only a small percentage of those diagnosed with different forms of depression benefits of specialized treatment. In the USA and Western Europe, approximately $20 \%$ of those received psychotherapy (Weddington, 1983; Brody et al., 1997) and almost half of the patients drop out of therapy before completion. The major impediments in receiving treatment are: financial expenses, availability of specialized therapist, especially for sub-syndromal symptomatology (Amstadter et al., 2009), perception of stigma associated with mental illness (Klein et al., 2009), lack of spatial and/or temporal access to therapy etc. (Przeworski and Newman, 2006).

Under these conditions, a very important mission of research and practice in mental-health care becomes the investigation of treatment methods, which are more accessible and cost-effective than traditional ones (Kazantzis and L'Abate, 2007). Recognizing the importance of timely interventions which would target recuperation and facilitate adaptive processes, the National Institute for Health and Clinical Excellence (NICE, 2002) has recommended several forms of psychotherapeutic interventions that proved to be highly effective in the amelioration of symptoms (Anderson, 2004; Litz et al., 2007).

\section{Therapeutic horticulture}

Presently, a rapid pace of urbanization may be noticed all around the world, with over half of the world's population living in urban areas (Bratman et al., 2015). In many societies, urbanization, resource exploitation and lifestyle changes have diminished the number of possibilities for humans to maintain contact with nature. Therapeutic horticulture activities were conceived to be person-centred in order to achieve evidence-based approaches in practice (Bragg and Atkins, 2016).

But, the two notions as Horticultural Therapy and Therapeutic Horticulture are often used interchangeably. The differences between them are that the Horticultural Therapy (HT) is centred on a specific person needs and implemented by trained therapists (Gonzalez et al., 2009), while Therapeutic Horticulture (TH) is a more open program defined as "a process that uses plant-related activities through which participants strive to improve their well-being through active or passive involvement" (Sempik et al., 2003; Gonzalez et al., 2009; Kam and Siu, 2010; Adevi and Mårtensson, 2013).

Studies reported strong evidence of restorative benefits by using nature as an alternative form of therapy (Hartig et al., 2014). Gardening was considered as the second most common and most popular outdoor activity among adults, older than 65 years (Sommerfeld et al., 2010). It may be considered part of a nature-based active horticulture therapy schedule, like as seeding and planting (Gonzalez et al., 2010; Kamioka et al., 2014), maintenance of green space (Gonzalez et al., 2009, 2011; Kam and Siu, 2010; Vujcic et al., 2017) and indoor ornamental plants (Kamioka et al., 2014).

A plethora of research indicates the existence of a significant relationship between the emergence of mental disorders and exposure to natural environments, highlighting the benefits of nature-based activities (e.g., gardening) on the physical, social, emotional and cognitive functioning (Ulrich, 1993; Frumkin, 2001; Patel et al., 2007; Annerstedt and Währborg, 2011). More specifically, less exposure to nature facilitates the development of different mental and emotional dysfunctions (Marsella, 1998; Annerstedt et al., 2010). Individuals residing in urban areas were found to be $38 \%$ more likely to develop a mental illness, $21 \%$ more likely to suffer from anxiety and 39\% more likely to develop a mood disorder than those living in rural areas (Wood et al., 2016). Briefly put, access to less green spaces may contribute to the experience of higher levels of stress (Roe et al., 2013).

These findings get serious implications if we consider that by 2050 urbanization will exceed $70 \%$ (Bratman et al., 2015). Traditionally, gardening activities are associated with the amelioration of stress symptoms, inducing mood relaxation and recovery from everyday tasks (van den Berg and Custers, 2011). Recently, research based on experimental studies indicate the existence of beneficial effects of activities conducted in nature, reducing selfreported anger, fatigue (Hartig et al., 2014), anxiety (Rodiek, 2002; Lee et al., 2004; Stepney and Davis, 2005; Kam and Siu, 2010; Song et al., 2010; Hartig et al., 2014), stress (Kam and Siu, 2010; van den Berg et al., 2010; Gonzalez et al., 2011; Hawkins et al., 2011) and depression (Son et al., 2004; Wichrowski et al., 2005; Gonzalez et al., 2009; Min et al., 2014; Ghanbari et al., 2015; Wood et al., 2016).

In mental illnesses, depression may be correlated with an imbalance in the kynurenine (KYN) pathway (Wurfel et al., 2017). Evidence-based research suggests that the KYN pathway may be implicated in the pathophysiology of depression. Réus highlights the importance of the kynurenine pathway according to depression, based on the results obtained by clinical and preclinical studies (Réus et al., 2015). Based on the tryptophan metabolic pathway, kynurenine is generated by the tryptophan degradation, one of the precursors of serotonin (Ogyu et al., 2018), which can be a start to future research into alternative treatments for depression. Almost $99 \%$ of tryptophan contribution is transformed in the liver into kynurenine and kynurenic acid (Reus et al., 2015).

The major objective of the present pioneering study was to investigate the possible effect of a Therapeutic Horticulture intervention on people in depression amelioration. 
806

\section{Materials and Methods}

\section{Method design and participants}

The present study was an experimental research based on pre- and post-test assessments, conducted among randomly selected volunteer subjects at University of Agricultural Sciences and Veterinary Medicine ClujNapoca, Romania.

Hypothesis 1: it was intended to decrease the level of depression for the volunteer involved in Therapeutic Horticulture Intervention, measured with the Beck Depression Inventory, using BDI_T1 for the date collected before therapeutic horticulture investigation, and BDI_T2 after the last session.

Hypothesis 2: the expect results of the changes in the kynurenine pathway after the Therapeutic Horticulture Intervention the levels of depression measured through contribution of kynurenine and kynurenic acid to change significantly, based on the contribution of kynurenine (KYN_T1) and kynurenic acid (KYNA_T1) before and after (KYN_T2, KYN_T2) Therapeutic Horticulture Intervention.

Moreover, the study was conducted by measuring depression both on the subjective and the objective levels, in order to obtain more relevant information regarding the real change in depression levels. Consequently, the investigation of depression level was assessed with the Beck Depression Inventory (BDI) and doubled the obtained data by assessing the levels of biomarkers - kynurenine and kynurenic acid contribution obtained from biological samples (urine). We chose to investigate in a non-invasive way, the kynurenine and kynurenic acid levels based on the other research results which indicates that changes in these indicators may be related to changes in the levels of depressions.

In the first stage of the study were randomly selected an assessed 85 volunteer subjects with the Beck Depression Inventory questionnaire (BDI score) made by Beck (Beck and Steer, 1987). Thirty minutes after the distribution, the questionnaires were collected and coded. The age of the 85 participants ( 37 men, 48 women) ranged from 19 to 32 years ( $M=21.1$ years), $72 \%$ attaining $B D I$ scores $\leq 10$; the rest attaining BDI scores was above 10 . From the questioned participants $(\mathrm{N}=24)$ during the study, in the TH group were selected eight participants $(1$ man, 7 women) who attended 10 consecutive days (excepting Saturdays and Sundays). After completing the therapeutic horticulture sessions, biologic fluid - urine samples were collected by the participants and preserved in laboratory conditions (pre-post TH). All the participants who have done and finished the study declared that during the experimental period and until the post-test, none of them received any form of medical treatment, including also tryptophan.

\section{Research setting}

The study was part of a larger "green care and maintenance" program performed by subjects. For this research study, the University of Agricultural Sciences and Veterinary Medicine Cluj-Napoca green space was selected and used to perform therapeutic horticultural based activities.

\section{Procedures}

It was conducted a 2-week Therapeutic Horticulture (TH) program in 10 consecutive days (including 2 days of break in one week-end). It included ordinary and easy gardening activities, both active and passive. The active parts of the program included sowing, potting, planting, composing beds, rooting herbs and pruning orchard and vineyard planting. Similar activities were effectuated by Gonzalez et al., 2011. The passive parts included walking around, sitting on benches, watching birds, insects, butterflies, the weather and the landscape, activities use in other research studies (Kam and Siu, 2010; Cooper Marcus and Sachs, 2014; Vujcic et al., 2017). Participations in the project implied attendance in the TH activities every day in four-hour group sessions.

\section{Outcome measures}

Severity of depression was measured with the BDI, a 21item self-report questionnaire according to Beck Depression Inventory (Beck and Steer, 1987). The maximum score on the BDI accepted is 63 and the instrument further demonstrates good discrimination between patients with varying degrees of depression, and it accurately reflects changes in depression severity over time (Gonzalez et al., 2011). Also, the participants of the research study were asked to bring urine sample (first urine in the morning, of the same day), at the first and last $\mathrm{TH}$ program activities. Each biological urine sample was processed in the Spectroscopy Laboratory of Life Sciences Institute, where were analysed the urinary biomarkers like tryptophan, tryptophan-related metabolites pathway concentration by high performance liquid chromatography with fluorimetric detection. Thus, our study was based on the research of Ogyu et al. (2018) which reported that the biological mechanisms underlying depression should be explored to lead to the development of a more effective treatment strategy for depression, abnormalities of the kynurenine (KYN) pathway may be implicated in the pathophysiology of this disease.

\section{Beck depression inventory-II}

Depressive tendencies were measured with the Beck Depression Inventory-II (BDI) used by Beck (Beck et al., 1979; Romanian adaptation David and Dobrean, 2012). The BDI contain 21-item, multiple-choice format inventory, designed to measure the presence of depression in adults and adolescents. Each of the 21 items assesses a symptom or attitude specific to depression, inquiring its somatic, cognitive, mood and behavioural aspects. By its assessments, single scores are produced, which indicate the intensity of the depressive episode. Scores ranging from 0 to 9 represent normal levels of depression. Scores situated between 10 and 18 represent mild to moderate depression; values between 19 and 29 represent moderate to severe depression, while scores above the value of 30 represent severe depression. Internal consistency indices of the BDI are usually above 90 . 


\section{Ethical considerations}

The research study was approved by the Committee for Bioethics in University of Agricultural Sciences and Veterinary Medicine Cluj-Napoca, Romania. The volunteer subjects provided written informed consent, and they received printed information about the research study. All data were analysed in a confidential manner, without imparting private matters of the subjects involved.

\section{Spectrofluorimetry analysis}

The spectrofluorimetric analysis of urine from nondepressed and depressive patients was performed with a Jasco FP 8200 spectrofluorometer. It was analysed a quantity of $2 \mathrm{ml}$ of urine without prior centrifugation. In order to obtain not only a proper emission for kynurenic acid (KYNA) and kynurenine (KYN), but also a good comparison between the collected urine samples, several excitation wavelengths $\left(\lambda_{\mathrm{ex}}\right)$ were used $(330$ and $380 \mathrm{~nm}$ ). The emission spectra were recorded in a range of 345 to 750 $\mathrm{nm}$, for KYNA and of 395 to $750 \mathrm{~nm}$ for KYN, with maximum of emission at $380 \mathrm{~nm}$ for KYNA and at $480 \mathrm{~nm}$ for KYN respectively as described in dedicated literature
(Lesniak et al., 2013). The gathered spectra were further fitted with the Gaussian deconvolution algorithm as illustrated in Fig. 1 and 2, where can be seen a deconvolution example made on one of participants biological sample, collected before and after the $\mathrm{TH}$ intervention, using spectrofluorimetric analysis. The OriginPro Version 8.5.1 OriginLab Corporation, Northampton, MA, USA was used to analyse the fluorescence data in order to obtain the contribution of searched fluorophores to the total fluorescence of urine samples (KYN and KYNA).

\section{Results}

Based on the investigations made by measuring the effects of the therapeutic horticulture investigation, to achieve changes in the BDI score and contribution of the fluorophores in the kynurenine pathway, the evidencebased research reveals that TH can have a possible positive effect decreases in depression level. By measuring depression on both the subjective and the objective levels, it was obtained more relevant information regarding the real

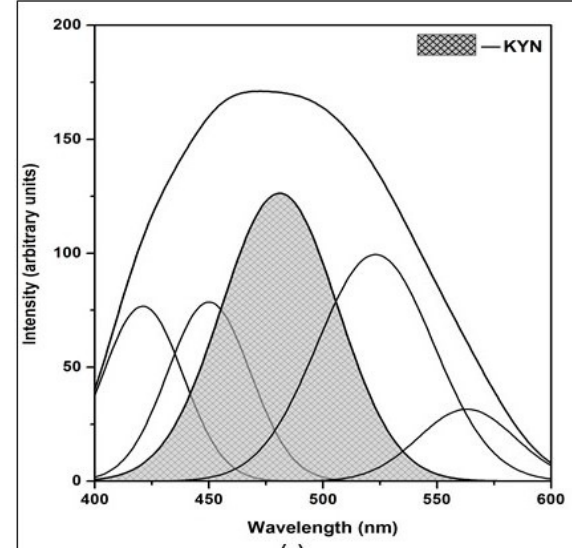

(a)

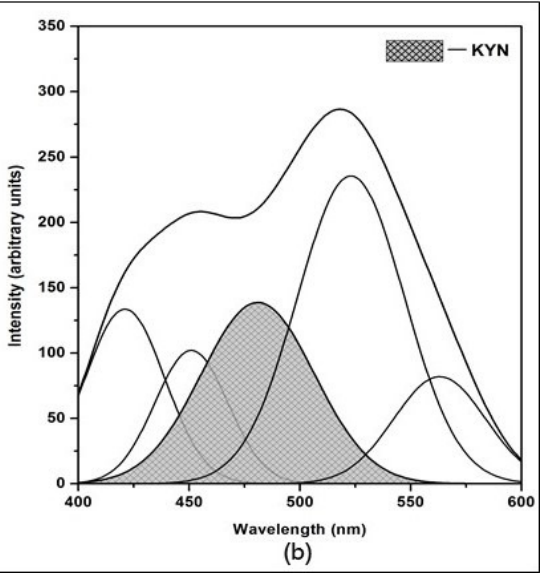

Fig. 1. The deconvoluted urine spectra of one subject collected before (a) and after (b) the therapeutic horticulture intervention, concerning the kynurenine contribution

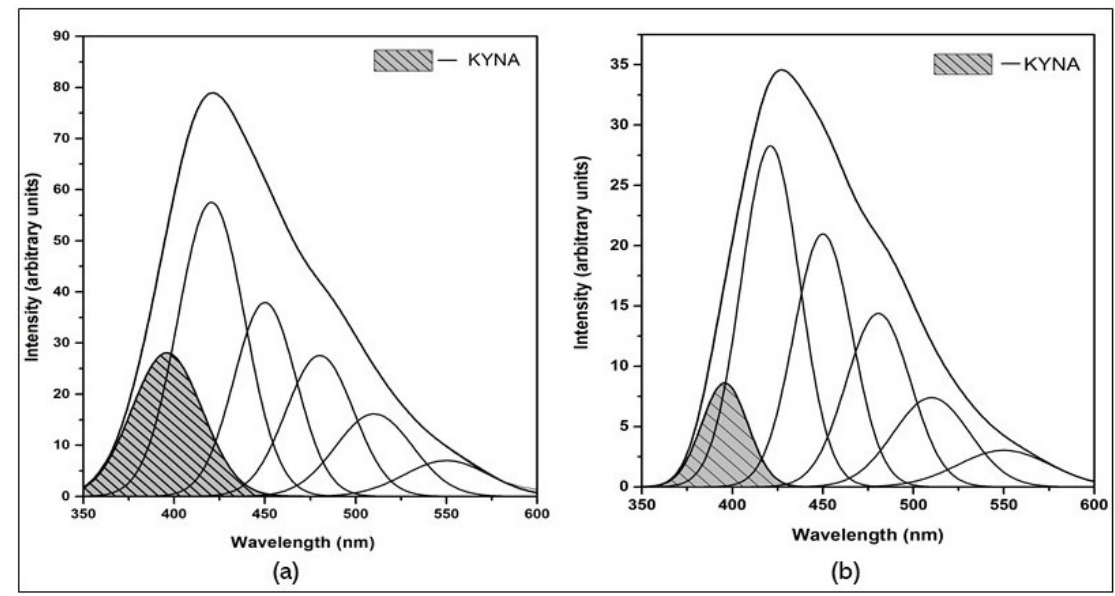

Fig. 2. The deconvoluted urine spectra of one subject collected before (a) and after (b) the therapeutic horticulture intervention, concerning the kynurenic acid contribution 
Table 1. Descriptive statistics analysis according to the collected data during therapeutic horticulture intervention

\begin{tabular}{cccccc}
\hline \multirow{2}{*}{ Measure } & Measurement & \multicolumn{3}{c}{ Value } \\
\cline { 3 - 6 } & point & Min. & Max. & Mean & St. Dv. \\
\hline BDI & T1 & 10.00 & 22.00 & 14.00 & 3.77 \\
BDI & T2 & 5.00 & 11.00 & 7.87 & 2.41 \\
KYN & T1 & 26.23 & 44.85 & 33.48 & 5.64 \\
KYN & T2 & 24.11 & 40.11 & 33.27 & 4.83 \\
KYNA & T1 & 7.88 & 31.07 & 20.60 & 7.26 \\
KYNA & T2 & 12.90 & 26.64 & 18.02 & 4.72 \\
\hline
\end{tabular}

Table 2. Pre and post-test differences in levels of depression (BDI, KYN, KYNA) during therapeutic horticulture intervention

\begin{tabular}{cccc}
\hline & BDIT2 - BDIT1 & KYNT2 - KYNT1 & KYNAT2 - KYNAT1 \\
\hline$Z$ & $-2.37^{*}$ & -0.56 & -0.98 \\
$p$ & 0.018 & 0.575 & 0.327 \\
\hline
\end{tabular}

change in depression levels. Consequently, depression was assessed with the Beck Depression Inventory (BDI) and doubled the obtained data by assessing the levels of kynurenine and kynurenic acid obtained from urine samples.

The investigation of the kynurenine and kynurenic acid levels with a non-invasive procedure is relevant based on the literature which indicates that changes in the contributions of these markers may be related to changes in the levels of depressions (Reus et al., 2015; Ogyu et al., 2018). Firstly, it was presented the descriptive characteristics of the data processed with SPSS 20.0 (Table 1).

According to the data obtained, the mean value of BDI score measured with the Beck Depression Inventory dropped off from 14.00 (mild to moderate depression) to 7.87 (normal levels of depression). Concerning the spectrofluorimetric analysis, it can be noticed that the contribution of either kynurenine (KYN) and kynurenic acid (KYNA) in the urine sample collected pre-test, and post-test, before and after Therapeutic Horticulture Intervention were lower. The obtain result are similarly as other research studies (Gabbay et al., 2010; Raison et al., 2010; Sublette et al., 2011; Myint et al., 2013; Savitz et al., 2015). Previous similar studies noted by Ogyu et al., 2018 showed an abnormal contribution of KYNA and QUIN, relevant metabolites of KYN pathway, in subjects with depression.

Wilcoxon non-parametric t-test for 2 related samples was used consequently to the number of participants in the present experiment. The results obtained were presented in Table 2.

Obtained results indicate that only depression measured with the Beck Depression inventory has changed significantly $\left[\mathrm{Z}=-2.37^{*}, p<0.05\right]$, decreasing from Mean $\mathrm{T} 1=14.00$ to Mean T2 $=7.87$. The effect size $(\mathrm{r}=0.59)$ of this decrease was calculated with the following formula: $\mathrm{r}=$ $\mathrm{Z} / \sqrt{ } \mathrm{N}$ (where, $\mathrm{N}=$ number of participants ${ }^{*}$ number of observations), which according to Cohen's (1988) classification is a large statistical effect.

Analysing the results, it may be observed that changes in the concentration of either kynurenine or kynurenic acid between the two assessments are not significant. The results indicated a decrease in the levels of kynurenine $\left(\mathrm{T} 1_{\text {mean }}=\right.$ $\left.33.48, \mathrm{~T} 2_{\text {mean }}=33.27\right)$ and kynurenic acid contribution $\left(\mathrm{T} 1_{\text {mean }}=20.60, \mathrm{~T} 2_{\text {mean }}=18.02\right)$, however this change has not proved significant.

Continuing the investigation, it was noticed that most of the participants presented a pattern of depression symptoms decrease; moreover, depression dropped with a category of severity, from mild-moderate to normal (Fig. 3).

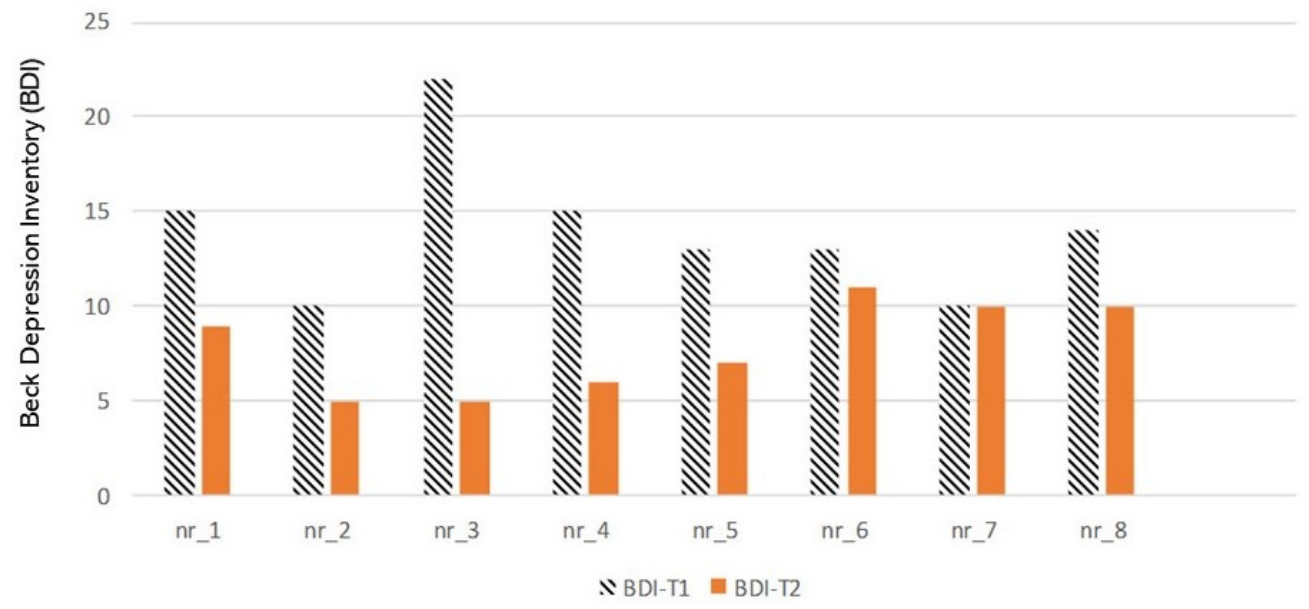

Fig. 3. Changes in BDI in individual cases of participants (BDI-T1, based on samples from the first day of the experiment; BDI$\mathrm{T} 2$, based on samples from the last day of the experiment, after the $\mathrm{TH}$ ) 
Analysing the results can be concluded that in the case of participant no. 1 the depression level dropped from 15 to 9 , in no. 2 from 10 to 5 , in no. 3 from 22 to 5 , in no. 4 from 15 to 4 , no. 5 from 13 to 7 , in no. 6 from 14 to 11 , in no. 8 from 14 to 10 in the case of participant no. 7 .

\section{Discussion}

The last four-five decades have witnessed an unprecedented increase in the number and the diversity of life-challenges. The number of those who cannot adequately adapt to these constant changes, and who suffers of mental illness of clinical intensity has been constantly increasing along the years, depression being one of the most frequently encountered mental illnesses (Andrade et al., 2003; Cuijpers et al., 2007; Cunningham et al., 2006; Weehuizen, 2008). Under these conditions, a very important mission of research and practice in mental-health care becomes the investigation of treatment methods, which are more accessible and cost-effective than traditional ones (Kazantzis and L'Abate, 2007). A relatively accessible, cost effective form of intervention is Horticulture Therapy (HT, or Therapeutic Horticulture, used interchangeably), which has received increased attention along the years, due to its relative simplicity and effectiveness.

The scientific results conclude that analysing the kynurenine pathway after the tryptophan degradation, the changes can be implicated in the inflammation process in the major depressive disorder (MDD). Based on the connection between tryptophan degradation, MDD and inflammatory mediators can be a purpose for antidepressant therapies (Dantzer et al., 2011; Zheng et al., 2013; BayRichter et al., 2015). Latest research studies indicate that kynurenine pathway can be a biomarker to evidence neurological diseases (Fujigaki et al., 2017). Different contribution of kynurenine can be involved in depression. More research is needed to highlight the connection between depression and each metabolite of the KYN pathway (Ogyu et al., 2018).

The main findings of the present study indicate that the levels of depression measured with the BDI have significantly decreased after the Therapeutic Horticulture Interventions. An even better result regards the fact that the significance of this change was not only statistical, but also clinical, since most of the participants felt from a higher depression category into a lower one, as established by cutpoints. No significant change during and after a 10-day Therapeutic Horticulture session was achieved in the kynurenine pathway.

Possible reasons for this finding may be (the short interval, the implication of the participants, the personal and subjective factors or metabolism), while this research did was not analyse the participants diet during the $\mathrm{TH}$ intervention. However, while there was no significant difference in kynurenine and kynurenic acid contribution (Myint et al., 2007), further research is clearly needed (Reus et al., 2015; Ogyu et al., 2018).

In the scientific literature, for the sample preparation were used different fluids to analyse the kynurenine pathway (KYNA, QUIN or KYN) in blood (serum and plasma), urine, cerebrospinal fluid (CSF) and brain tissue samples. Using the listed biofluids, results obtained at subjects with depression in comparison with HCs. Namely, the kynurenine contribution was expected to significantly increase (Myint et al., 2007; Raison et al., 2010; Hennings et al., 2013; Quak et al., 2014; Nikkheslat et al., 2015; Hu et al., 2016; Veen et al., 2016; Krause et al., 2017), and the levels of kynurenic acid to increase (Myint et al., 2007; Maes et al., 2011; Bay-Richter et al., 2015; Nikkheslat et al., 2015; Schwieler et al., 2015; Young et al., 2016).

The partial conformation of the results may be due to several limitations of the hereby experiment: (i) the number of participants has been relatively low (Gigliotti $e t$ al., 2004; Rodiek et al., 2008); however, in this domain many studies did not include a control group; (ii) the QUIN levels in urine was not investigated in the present study, which may be more directly linked to changes in biomarker kynurenine pathway (Reus et al., 2015; Ogyu et al., 2018). As for future directions, the authors intend to increase the number of participants, to include a control group and to use as objective marker of depression the QUIN levels.

\section{Conclusions}

The obtained results indicated that the levels of depression measured with the BDI have significantly decreased after the Therapeutic Horticulture Interventions, the effect size of this decrease being quite large at the volunteer subjects. An even better result regards the fact that the significance of this change was not only statistical, but also clinical. Based on the biological biomarkers analysis of kynurerine and kynurenic acid contributions, differences were observed, but even though results did not indicate statistical changes. Therapeutic Horticulture Interventions is a possible alternative therapy to increase people well-being measured by a non-invasive method.

\section{Acknowledgements}

The present paper was published under the frame of the Collegium Talentum 2018 Programme of Hungary.

\section{Conflicts of interest}

The authors declare that there are no conflicts of interest related to this article.

\section{References}

Adevi AA, Mårtensson F (2013). Stress rehabilitation through garden therapy: the garden as a place in the recovery from stress. Urban Forestry and Urban Greening 12(2):230-237.

Albert PR (2015). Why is depression more prevalent in women? Journal of Psychiatry \& Neuroscience 40(4):219-221.

Aldwin CM (2007). Stress, coping, and development: an integrative perspective.UKGuilford, London.

Amstadter AB, Broman-Fulks J, Zinzow H, Ruggiero KJ, Cercone J (2009). Internet based interventions for traumatic stress-related mental health problems: a review and suggestions for future research. Clinical Psychology Review 29(5):410-420. 
810

Amundson N (2006). Challenges for career interventions in changing contexts. International Journal for Educational and Vocational Guidance 6(1):3-14.

Anderson NB (2004). Encyclopedia of health and behavior. Vol. 1. Sage.

Andrade L, Caraveo-Anduaga JJ, Berglund P, Bijl RV, de Graaf R, Vollebergh W, ... Wittchen HU (2003). The epidemiology of major depressive episodes: Results from the International Consortium of Psychiatric Epidemiology (ICPE) Surveys. International Journal of Methods in Psychiatric Research 12(1):3-21.

Annerstedt M, Norman J, Boman M, Mattsson L, Grahn P, Währborg P (2010). Findingstress relief in a forest. Ecological Bulletins 53:33-42.

Annerstedt M, Währborg P (2011). Nature-assisted therapy: Systematic review of controlledand observational studies. Scandinavian Journal of Public Health 39(4):371-388.

Banyard VL, Edwards VJ, Kendall-Tackett KA (2009). Understanding the effects of extreme stress and of psychological harm. NY: Routledge, New York.

Bay-Richter C, Linderholm, KR, Lim CK, Samuelsson M, TräskmanBendz L, Guillemin GJ, ... Brundin L (2015). A role for inflammatory metabolites as modulators of the glutamate N-Methyl- D -Aspartate receptor in depression and suicidality. Brain Behavior and Immunity 43:110-17.

Beck AT, Steer R (1987). Manual for the Beck Depression Inventory. San Antonio, TXPsychological Corporation.

BraggR, Atkins G (2016). A review of nature-based interventions for mental health care. Natural England Commissioned Reports, pp 204.

Bratman GN, Daily GC, Levy BJ, Gross JJ (2015). The benefits of nature experience: improved affect and cognition. Landscape and Urban Planning 138:41-50.

Brody DS, Khaliq AA, Thompson TL (1997). Patients' perspectives on the management of emotional distress in primary care settings. Journal of General Internal Medicine 12(7):403-406.

Cohen J (1988). Statistical Power Analysis for the Behavioral Sciences. New York: Lawrence Erlbaum Associates.

Cooper Marcus C, Sachs NA (2014). Therapeutic landscapes: An evidencebased approach to designing healing gardens and restorative outdoor spaces. Vol. 1.John Wiley \& Sons.

Cuijpers P, Smit F, van Straten A (2007). Psychological treatments of subthreshold depression: A meta-analytic review. Acta Psychiatrica Scandinavica 115(6):434-441.

Cunningham M, Rapee R, Lyneham H (2006). Feedback to a prototype self-help computer program for anxiety disorders in adolescents. Advances in Mental Health 5(3):216-224.

Dantzer, R, O'Connor JC, Lawson MA, Kelley KK (2011). Inflammationassociated depression: from serotonin to kynurenine. Psychoneuroendocrinology36(3):426-436.

David D, Dobrean A (2012). Inventarul de depresie Beck-(BDI-II). Romanian Psychological TestingServices.

Falvo D (2005). Medical and psychosocial aspects of chronic illness and disability $\left(3^{\text {rd }} \mathrm{Ed}\right.$.). Sudbury, MA:Jones and Bartlett.

Fujigaki H, Yamamoto Y, Saito K (2017). L-Tryptophan-Kynurenine pathway enzymes are therapeutic target for neuropsychiatric diseases: focus on cell type differences. Neuropharmacology 112:264274.
Gabbay V, Liebes L, Katz Y, Liu S, Mendoza S, Babb JS, Klein RG, Gonen O (2010). The kynurenine pathway in adolescent depression: preliminary fi ndings from a proton MR spectroscopy study. Progress in Neuropsychopharmacology and Biological Psychiatry 34(1):37-44.

Ghanbari S, Jafari F, Bagheri N, Neamtolahi S, Shayanpour R(2015). Study of the effect of using purposeful activity (gardening) on depression of female resident in Golestan Dormitory of Ahvaz Jundishapur University of Medical Sciences. Journal of Rehabilitation Sciences and Research 2(1):8-11.

Gigiotti CM, Jarrott, SE, Yorgason J (2004). Harvesting health. Dementia $3(2): 161-180$.

Gonzalez MT, Hartig T, Patil GG, Martinsen EW, Kirkevold M (2009). Therapeutic horticulture in clinical depression: a prospective study. Research and Theory for Nursing Practice: An International Journal 23(4):312-328.

Gonzalez MT, Hartig T, Patil GG, Martinsen EW, Kirkevold M (2010). Therapeutic horticulture in clinical depression: a prospective study of active components.Journal of advanced Nursing 66(9):2002-2013.

Gonzalez MT, Hartig T, Patil GG, Martinsen EW, Kirkevold M(2011). A prospective study of existential issues in therapeutic horticulture for clinical depression. Issues in Mental Health Nursing 32(1):73-81.

Gustavsson A, Svensson M, Jacobi F, Allgulander C, Alonso J, Beghi E, ... Olesen J (2011). Cost of disorders of the brain in Europe 2010. European Neuropsychopharmacology 21(10):718-779.

Hartig T, Mitchell R, De Vries S, Frumkin H (2014). Nature and health. Annual Review of Public Health 35:207-228.

Hawkins JL, Thirlaway KJ. Backx K, Clayton DA (2011). Allotment gardening and other leisure activities for stress reduction and healthy aging. Hort Technology 21(5):577-585.

Hennings A, Schwarz MJ, Riemer S, Stapf TM, Selberdinger VB, RiefW (2013). Exercise affects symptom severity but not biological measures in depression and somatization-results on IL-6, neopterin, tryptophan, kynurenine and 5-HIAA. Psychiatry Research 210(3):925-933.

Hennings A, Schwarz MJ, Riemer S, Stapf TM, Selberdinger VB, Rief W (2013). Exercise Affects symptom severity but not biological measures in depression and somatization - results on il-6, neopterin, tryptophan, kynurenine and 5-HIAA. Psychiatry Research 210(3):925-33.

Hu LJ, Li XF, Hu JQ, Ni XJ, Lu HY, WangJJ, Wen YG (2017). A simple HPLC-MS/MS method for determination of tryptophan, kynurenine and kynurenic acid in human serum and its potential for monitoring antidepressant therapy. Journal of Analytical Toxicology 41(1):37-44.

Kam MCY, Siu AMH (2010). Evaluation of a horticultural activity programme for persons with psychiatric illness. Hong Kong Journal of Occupational Therapy 20(2):80-86.

Kamioka H, Tsutani K, Yamada M, Park H, Okuizumi H, Honda T, ... Mutohi Y (2014). Effectiveness of horticultural therapy: a systematic review of randomized controlled trials. Complementary Therapies in Medicine 22(5):930-943.

Kazantzis N, L'Abate L (2007). Handbook of homework assignments in psychotherapy: Research, practice, prevention. New York, NY, US: Springer.

Kendall-Tackett K (2009). Psychological trauma and physical health: A psychoneuroimmunology approach to etiology of negative health effects 
and possible interventions. Psychological Trauma: Theory, Research, Practice, and Policy 1(1):35-48.

Kessler RC, Berglund P, Demler O, Jin R, Koretz D, Merikangas KR, ... WangPS (2003). The epidemiology of major depressive disorder: results from the National Comorbidity Survey Replication (NCS-R). Jama 289(23):3095-3105.

Klein B, Mitchell J, Gilson K, Shandley K, Austin D, Kiropoulos L, ... Cannard G (2009). A therapist-assisted internet-based CBT intervention for posttraumatic stress disorder: Preliminary results. Cognitive Behavior Therapy 38(2):121-131.

Krause D, Myint AM, Schuett C, Musil R, Dehning S, Husain MI, Müller N (2017). High kynurenine (a Tryptophan Metabolite) predicts remission in patients with major depression to add-on treatment with celecoxib. Frontiers in Psychiatry 8(16)1-7.

Lanius RA, Vermetten E, Pain C (2010). The impact of early life trauma on health and disease: The hidden epidemic. Cambridge, UK: Cambridge University Press.

Lee YH, Ro MR, Lee YS (2004). Effects of horticultural activities on anxiety reduction of female high school students. Acta Horticulturae 639:249251.

Lesniak WG, Jyoti A, Mishra MK, Louissaint N, Romero R, Chugani DC, ... Kannan RM (2013). Concurrent quantification of tryptophan and its major metabolites. Analytical Biochemistry 443(2):222-231.

Levenson JL (2006). Essentials of psychosomatic medicine. Arlington, VA: American Psychiatric Publishing.

Litz BT, Engel CC, Bryant RA, Papa A (2007). A randomized, controlled proof-of-concept trial of an internetbased, therapist-assisted selfmanagement treatment for posttraumatic stress disorder. American Journal of Psychiatry 164(11):1676-1683.

Maes M, Galecki P. Verkerk R, Rief W (2011). Somatization, but not depression, is characterized by disorders in the tryptophan catabolite (TRYCAT) pathway, indicating increased indoleamine 2, 3dioxygenase and lowered kynurenine aminotransferase activity. Neuro Endocrinology Letters 32(3):264273.

Marsella AJ (1998). Urbanization, mental health, and social deviancy: a review of issues and research. American Psychologist 53(6):624634.

Mathers CD, Loncar D (2006). Projections of global mortality and burden of diseasefrom 2002 to 2030. PLoS Medicine 3(11):442.

Min S, Hu JY, Kang JH, Kang HY (2014). The effects of horticultural therapy on the well-being and hope of women in rural Korea. Journal of Nursingand Care 3(06):1000214.

Myint AM, Bondy B, Baghai C, Eser D, Nothdurfter C, Schüle C, ... Schwarz MJ (2013). Tryptophan metabolism and immunogenetics in major depression: a role for interferon- $\gamma$ gene. Brain, Behaviour, and Immunity 31:128-133.

Myint YK, Verkerk R, Scharpé S, Steinbusch H, Leonard B (2007). Kynurenine pathway in major depression: evidence of impaired neuroprotection. Journal of Advanced Nursing 98(1-2):143-151.

National Institute for Clinical Excellence (NICE) (2002). Guidance on the use of computerized cognitive behavioral therapy for anxiety and depression. Technology Appraisal 51:1-38.

Nikkheslat N, Zunszain PA, Horowitz MA, Barbosa IG, Parker JA, Myint AM, ... Pariante CM (2015). Insufficient glucocorticoid signaling and elevated inflammation in coronary heart disease patients with comorbid depression. Brain, Behavior, and Immunity 48:8-18.

Nolen-Hoeksema $S$ (2003). Women who think too much. How to break free of overthinking and reclaim your life.London: Piatkus Books.

Ogyu K, Kubo K, Noda Y, Iwata Y, Tsugawa S (2018). Kynurenine pathway in depression: a systematic review and meta-analysis. Neuroscience and Biobehavioral Reviews 90:16-25.

Patel V, Flisher AJ, Hetrick S, McGorry P (2007). Mental health of young people: Aglobal public-health challenge. Lancet 369(9569):1302-1313.

Pennebaker JW, Chung CK (2011). Expressive writing: Connections to physical and mental health. Oxford Handbook of Health Psychology $417-437$.

Pratt LA, Brody DJ, Qiuping G (2011). Antidepressant use in persons aged 12 and over: UnitedStates, 2005-2008. NCHSData Brief76:1-8.

Przeworski A, Newman MG (2006). Efficacy and utility of computerassisted cognitive behavioral therapy for anxiety disorders. Clinical Psychologist 10(2):43-53.

Quak J, Doornbos B, Roest AM, Duivis HE, Vogelzangs N, Nolen WA, ... De Jonge $\mathrm{P}(2014)$. Does tryptophan degradation along the kynurenine pathway mediate the association between pro-inflammatory immune activity and depressive symptoms? Psychoneuroendocrinology 45:202210.

Raison CL, Dantzer R, Kelley KW, Lawson MA, Woolwine BJ, Vogt G, ... Saito K (2010). CSF concentrations of brain tryptophan and kynurenines during immune stimulation with IFN- $\alpha$ : relationship to CNS immune responses and depression. Nature-Molecular Psychiatry 15(4):393-403.

Reus GZ, Jansen K, Titus S, Carvalho AF, Gabbay V, Quevedo J (2015). Kynurenine pathway dysfunction in the pathophysiology and treatment of depression: evidences from animal and human studies. Journal of Psychiatric Research 68:316-328.

RodiekS(2002). Influence of an outdoor garden on mood and stress in older persons. Journal of Therapeutic Horticulture 13(1):13-21.

Roe J, Thompson C, Aspinall P, Brewer M, DuffE, Miller D, ... Clow A (2013). Green space and stress: evidence from cortisol measures in deprived urban communities. International Journal of Environmental Research and Public Health 10(9):4086-4103.

Savitz J, Dantzer R, Meier TB, Wurfel BE, Victor TA, Mcintosh SA, ... Drevets WC (2015). Activation of the kynurenine pathway is associated with striatal volume in major depressive disorder. Psychoneuroendocrinology 62:5458.

Savitz J, Drevets WC, Smith CM, Victor TA, Wurfel BE, Bellgowan PS, Bodurka J, Teague TK, Dantzer R (2015). Putative neuroprotective and neurotoxic kynurenine pathway metabolites are associated with hippocampal and amygdalar volumes in subjects with major depressive disorder.Neuropsychopharmacology 40(2):463-471.

Savitz J, Drevets WC, Wurfel BE, Ford BN, Bellgowan PSF, Victor TA, ... Dantzer R (2015). Reduction of Kynurenic acid to quinolinic acid ratio in both the depressed and remitted phases of major depressive disorder. Brain, Behavior, and Immunity 46:55-59.

Schwieler L, Larsson MK, Skogh E, Kegel ME, Orhan F, Sally A, ... Engberg $\mathrm{G}$ (2015). Increased Levels of il-6 in the cerebrospinal fluid of patients with chronic schizophrenia - significance for activation of the kynurenine pathway. Journal of Psychiatry and Neuroscience 40(2):126-134. 
812

Sempik J, Aldrige J, Becker S (2003). Social and therapeutic horticulture: evidence and messages from research. Leicestershire: Thrive and Centre for Child and Family Research, Loughborough University.

Sommerfeld AJ, Waliczek TM, Zajicek JM (2010). Growing minds: evaluating the effect of gardening on quality of life and physical activity level of older adults. HortTechnology 20(4):705-710.

Son KC, Um SJ, Kim SY. Song JE, Kwack HR (2004). Effect of horticultural therapy on the changes of self-esteem and sociality of individuals with chronic schizophrenia. Acta Horticulturae 639:185191.

Song MJ, Kim MY, Sim IS, Kim WS (2010). Evaluation of horticultural therapy on the emotional improvement of depressed patients by using heart rate variability. Korean Journal of Horticultural Science and Technology 28(6):1066-1071.

Stepney PM, Davis PM(2005). Mental health, social inclusion and the green agenda: An evaluation of a land-based rehabilitation project designed to promote occupational access and inclusion of service users in North Somerset, UK. Social Work in Health Care 39(3-4):375-397.

Sublette ME, Galfalvy HC, Fuchs D, Lapidus M, Grunebaum MF, Oquendo MA, ... Postolache TT (2011). Plasma kynurenine levels are elevated in suicide attempters with major depressive disorder. Brain, Behavior, and Immunity 25(6):1272-1278.

Ulrich RS (1993). Biophilia, biophobia, and natural landscapes. Washington DC:Island Press. The Biophilia Hypothesis 7:73-137.

van den Berg AE, Custers MHG (2011). Gardening promotes neuroendocrine and affective restoration from stress. Journal of Health Psychology 16(1):3-11.

van den Berg AE, van Winsum-Westra $M$, de Vries S, van Dillen SM (2010). Allotment gardening and health: a comparative survey among allotment gardeners and their neighbors without an allotment. Environmental Health 9(74):1-12.

Veen C, Mu A, Burgerhout KM, Schwarz MJ, Schütze G, Kushner SA, ... Bergink V (2016). Tryptophan pathway alterations in the postpartum period and in acute postpartum psychosis and depression. Journal of Affective Disorders 189:298-305.

Vujcic M, Tomicevic-Dubljevic J, Grbic M, Lecic-Tosevski D, Vukovic O, Toskovic O (2017). Nature based solution for improving mental health and well-beingin urban areas. Environmental Research 158:385-392.

Weddington WW (1983). Adherence by medical-surgical inpatients to recommendations for outpatient psychiatric treatment. Psychotherapy andPsychosomatics 39(4):225-235.

Weehuizen RM (2008). Mental capital. The economic significance of mental health. Maastricht: Universitaire Pers Maastricht.

WHO (2017). Depression and other common mental disorders - Global health estimates. Geneva: WHODocument Production Services.

Wichrowski M, Whiteson J, Haas F, Mola A, Rey MJ (2005). Effects of horticultural therapy on mood and heart rate in patients participating in an inpatient cardiopulmonary rehabilitation program. Journal of Cardiopulmonary Rehabilitation and Prevention 25(5):270-274.

Wittchen HU, Jacobi F, Rehm J, Gustavsson A, Svensson M, Jönsson B, ... Steinhausen HC (2011). The size and burden of mental disorders and other disorders of the brain in Europe 2010. European Neuropsychopharmacology21(9):655-679.

Wood CJ, Pretty J, Griffin M (2016). A case-control study of the health and well-being benefits of allotment gardening Journal of Public Health 38(3):336-344.

Woolfolk RL, Lehrer PM, Allen LA (2007). Conceptual issues underlying stress management. In Lehrer PM, Woolfolk RL, Sime WE (Eds), Principles and practice of stress management. New York, NY: Guilford pp3-15.

Wurfel BE, Drevets WC, Bliss SA, McMillin JR, Suzuki H, Ford BN, ... Savitz JB (2017). Serum kynurenic acid is reduced in affective psychosis. Nature-Translational Psychiatry7(5):1-8.

Young KD, Drevets WC, Dantzer R, Teague TK, Bodurka J, Savitz J (2016). Kynurenine pathway metabolites are associated with hippocampal activity during autobiographical memory recall in patients with depression. Brain, Behavior, and Immunity 56:335-342.

Zheng P, Chen JJ, Huang T, Wang MJ, Wang Y, Dong MX, ... Xie P (2013). A novel urinary metabolite signature for diagnosing major depressive disorder.Journal of Proteome Research 12(12):5904-5911. 